\title{
The Prevalence of Needle Stick/Sharp Objects Injury in Hospital Staff and Preventive Practices Taken into Consideration
}

\author{
Article by Badmus Omobolanle Tawakalit \\ Master of Public Health, Texila American University, Nigeria \\ E-mail:b4_badmus@yahoo.com
}

\begin{abstract}
Health care workers are at an increased risk of accidental needle stick injuries because of the environment in which they work.

Objective is to study the prevalence of needle stick injury in the hospital and preventive practices taken into consideration.

Cross-sectional study design used, in a secondary care hospital in kuje, Abuja, Nigeria. Participants were 161 doctors, nurses, lab technicians and hospital cleaners. Statistical analysis: chisquare test and proportions

High percentages (79.5\%) of health care workers were reported to have had one or more needle stick injuries in their career. The average number of the injuries ever found was like 3.85\% per health care workers. 36 (22.4\%) reported to have had needle stick injuries in the last one month. More than half claimed it was due to tiredness that caused the injury. Most of the injuries occurred during recapping, most washed the site of injury with soap and water while few did nothing. Only 10 took post exposure prophylaxis of HIV/AIDS after their injury.

In conclusion occurrence of needle stick injuries were found to be common. Recapping of needles which is an avoidable practice was found to be part of the contributing factor to the injuries.

Therefore prevention of needle stick injuries is an integral part of preventive programs and training and retraining of hospital staff for safety practices in handling needles and sharp objects needs to be continuous in the hospital.
\end{abstract}

\section{Introduction}

Needle stick injuries are injuries caused by accidental needle puncture into the skin. This is a form of occupational hazard for people who work with hypodermic syringes and other needle equipment. The injuries can occur at any time when people use, disassemble or dispose needles. Needle stick injuries also known as percutaneous injuries or percutaneous exposure incidence to a sharp object or needles penetrating into the skin ,the sharp object or needles which was in contact with blood, body fluid or tissue of a client or patient.

Other sharp objects other than needles used in the hospital settings include items like scalpels, lancets, razor blades, scissors, metal wires, pins, cutters and staples.

When all these sharp objects are not disposed properly, they can become concealed in the garbage or linen causing injury to workers who encounter them unexpectedly.

Accidental punctures by these contaminated sharp objects can inject hazardous fluids into the body.

The major blood-borne pathogens that are of concern in needle stick injury are Hepatitis B virus, Hepatitis C virus and HIV, however there are some other infectious agents which could be bacteria or fungi that also have potential to transmit through needle injuries, few of which are syphilis, toxoplasmosis, diphtheria, brucellosis etc.

Injuries can occur at any stage of using, assembling, disassembling or disposing the items. It could when trying to access an intravenous line or when taking sample for investigations or during insertion or removal of needle. This can also occur during clean up that affect the cleaners most often when left in an unusual location. It is also common during surgical procedures when there is collision with sharps or co-workers, or during transfer of equipment or when suturing. 
Texila International Journal of Clinical Research

Volume 3, Issue 2, Dec 2016

So the nature of the procedure, staff experience in handling sharps and disposal of this sharps are all factors that influences these occurrences.

Preventing these injuries should be a paramount concern in health policy and is the most effective way to protect works.

\section{Objective}

Promoting the use of preventive practices in preventing occupational health injury from needlestick and sharps in the hospital settings.

\section{Methodology}

A comprehensive sharps injury prevention program conducted to recommend guidelines, effective disposal system, employee training and safe recapping procedures.

\section{What is occupational health hazards?}

Occupational health hazards are occupational illnesses that results from exposure in the workplace to physical, chemical or biological agents to the extent that the health of the worker is affected .In the case of the occupational health hazards in the hospitals, there are various hazards which the health workers are exposed to, few of which include accident (explosion, fires, needle sticks and sharps injuries), radiation, exposure to noxious chemicals and even assaults.

There are areas of special exposure to health hazards in the health services, which increases the risk of health hazards; these areas include accident and emergency services, ambulance care services, mental health institution, the prison services, care of elderly or attending to aggressive patient.

Also some activities increases risk of hazard in health works. Activities such as taking specimen of blood, body fluid, surgical procedures, dressing or treatment of wound, handling sharp instrument and handling health care waste.

Other physical and environmental hazards common in the hospital are slippery floors, noise, poor lighting, and inadequate ventilation. ${ }^{5}$

Blood happens to be the body fluid that presents the greatest risk of infection to health care workers.

Blood borne pathogens happen to be the microorganisms that transmit diseases by contact with blood. Contact could be by direct such as needle sticks or splash, or indirect as at when the mucous membrane comes in contact with a contaminated blood.

The most common conditions are Hepatitis C and B and Human Immunodeficiency virus (HVS).

\section{What are the hazards of needle stick and sharps injuries}

Needle sticks and other sharps injuries continue to be a significant hazard in the hospital settings, which exposes workers to blood borne pathogens.

It is estimated that millions of healthcare workers and related occupations are at risk of occupational exposure to blood borne pathogens.

According to the Center for Disease Control and Prevention (CDC), about 385,000 sharps injuries occur annually in hospital workers. ${ }^{6}$

Blood borne pathogens: are pathogenic microorganisms present in the human blood that can cause diseases in human. Examples of these pathogens include Human Immunodeficiency Virus (HIV), Hepatitis C (HCV), Hepatitis B Virus (HBV) and others.

The exposure of human blood to these pathogens is mostly because of unsafe needle devices, improper handling and disposal of needles and other sharps.

Contaminated Sharps are any contaminated object that can penetrate the skin these includes but not limited to needles, scalpels, broken glass, broken capillary tubes and exposure to dental wires. Exposure could also be from used disposable razors that could be contaminated with blood or I.V connector system that uses needles to connect I.V. setups. 


\section{How can the injuries be prevented}

In preventing needle stick injuries in the health care system there are some processes for selecting and evaluating needle devices with safety features, this processes include:

Forming a multidisciplinary team that will include workers to develop, implement and evaluate a plan to reduce the occurrence of the needle stick injuries in the institution.

Identifying priorities based on the assessment of how the needle stick injuries occurs, the patterns of device used. Settling the needle device with safety features.

When selecting a safe device, it's important to identify its intended scope of use in the health facility. Conducting a product evaluation.

Training and retraining of staff in the correct use of the devices

Monitor the use of new devices, after it is introduced to determine if additional training is needed.

Practicing standard practices, in work practice control in minimizing exposure to blood borne pathogens

Personal protective equipment

Proper handling and contamination of sharps.

Using safe needle container near areas needles are often found and used

Making vaccines and vaccination series of hepatitis B vaccines available for all employees

Post exposure evaluation and follow up.

Syringes: used syringes with needle stick features should never be recapped and they should be disposed in sharps containers after used or it could be destroyed using electrical equipment.

Sharp containers: must be provided in all areas where sharps are used. They must be closable, must resist puncture, leak proof and free from contaminant. This should be changed when it's about three quarterly full. It should be easy to access.

Blood collection: injuries from blood collection can be reduced by the use of needle shields, selfblunting needles, hinged needle shield or butterfly needles.

Sutures needles: sutures needles with blunt tips reduces the risk of needle sticks injuries by $69 \%$ and are recommended to reduce percutaneous injuries ${ }^{7}$.

PPE: gloves, gowns and eye and face should be protected, in adequate quantities and at no cost to the employers, that's depending on the part of the body that is exposed.

Vaccination and Treatment: workers at risk of blood borne exposure should be offered HBV vaccines, since this can protect from infection. In the case of HIV exposure, post exposure prophylaxis should be made available within two hours of exposure.

Surveillance Program: this program should provide in-depth analysis of accidents and are important tool for obtaining information, such program's goals are to determine the rate of injuries, investigating the factors that causes the injuries, ensuring workers that are injured gets proper treatments, identifying areas where preventive programs needs to be improved ${ }^{1}$.

\section{Occupational safety and hygiene}

Occupational safety and hygiene is a multidisciplinary field that is concerned with the safety, health and welfare of workers.

Health care workers are exposed to many hazards that affect their health and well-being ${ }^{10}$.

Occupational safety and hygiene practices vary in different nations with different legislation, regulations, enforcement and incentives for compliance, some states promotes this by providing public monies as subsides, grants or financing, while others do it by creating tax systems incentives. The US Occupational Safety and Health Administration (OSHA) estimates 5.6 million workers in the healthcare industry are at risk of occupational exposure to blood borne disease via percutaneous injuries $^{9}$

The roles and responsibility of occupational safety and hygiene professionals includes evaluating work environment, developing measures that might prevent injuries and illnesses in the work place, 
providing medical examinations and assessing the success of health workers program. There also provide information on occupational hygiene and safety risks in the work place.

Four certified service providers are required for this profession, this includes;

A safety professional

An occupational hygienist

An occupational physician

A work and organization specialist. ${ }^{9}$

The safety professional should be able to assess risk in the work place. This assessment should include identification of the hazard, identifying all staff affected by these hazards, evaluating the risk and identifying and prioritizing appropriate control measures. ${ }^{9}$

\section{Basic findings}

Study conducted among hospital staff of Kuje General Hospital Kuje, Abuja in September 2016.

Responded were 161 health care workers consisting of doctors, nurses and laboratory technicians and hospital cleaners.

About 79.5\% (128) of health care workers have being reported to have had one or more needle sticks injuries in their career.

In an average the number of needle stick injuries ever found was $3.85 \%$ per health care worker $\left(^{+}\right.$ 3.29SD).

For workers who had been working for at least 1 year, the mean number of injuries was as high as 4.5(+_3.4SD), 36(22.4\%) workers was said to have had needle stick injuries in the last 1 month.

These injuries occurred more among the doctors (25.6\%), Lab technicians (24.6\%) and Nurses (20, $5 \%$ ), most of which they didn't know the status of the patients.

Among them 2\% (17.5\%)were said to have had needle stick injuries from high risk patients with HIV, Hepatitis B and C, was more among doctors (21\%) and lab scientist (9.7\%).

Among the 128 who have had needle stick injuries, 35 (27.3\%) were not wearing gloves at the time it occurred.

About 103 (84.8\%) of them accepted that it was caused by self while the remaining $15.6 \%$ said it was someone else. Majority was caused by hollow-bore type of needle (89, 69.5\%) while about 30.5\% were from solid-bore needles. It is believe that hollow-bore needles are more efficient in transmitting bloodborne infection than solid needles such as suture ${ }^{3,5}$

Regarding time of injury most of the injuries occurred during the use (29.4\%), while greater part was after use, but before disposal $(83,65.5 \%)$ only few $5 \%$ occurred during disposal.

The cause of injury was asked, it was found that more than half was due to Fatigue(50.4\%) about $10.9 \%$ believed the injuries could have being prevented, most occurred during recapping(34.0\%). 37 cases occurred during handling of needles, 27 during collision with another person and 39 due to manipulation of patient.

\begin{tabular}{|lll|}
\hline Causes of the recent needle stick injuries $(\mathrm{n}=128)$ & & \\
Causes of injury & $\mathrm{N}$ & $\%$ \\
Fatigue & 64 & 50.4 \\
Rushed & 16 & 11.7 \\
Lack of assistance & 34 & 27.0 \\
Could have been prevented & 14 & 10.9 \\
\hline
\end{tabular}




\begin{tabular}{|c|c|c|c|c|}
\hline \multicolumn{5}{|c|}{$\begin{array}{l}\text { Responses of staff to different questions on needle stick injure. ( } \mathrm{n}=161 \text { who } \\
\text { had the needle stick injury). }\end{array}$} \\
\hline$\underline{\text { Doctors }}$ & nurses & $\underline{\text { lab }}$ & $\underline{\text { scientists }}$ & cleaners \\
\hline $\begin{array}{l}\text { Proportion who had injury } \\
\text { within the last } 1 \text { month }\end{array}$ & 25.6 & 20.5 & 24.6 & 26.6 \\
\hline $\begin{array}{l}\text { Proportion who had been } \\
\text { wearing gloves }\end{array}$ & 84.3 & 65.5 & 29.4 & 77.6 \\
\hline $\begin{array}{l}\text { proportion who received their } \\
\text { injury during recapping }\end{array}$ & 36.5 & 29.2 & 48.4 & 28.6 \\
\hline $\begin{array}{l}\text { Proportion who reported the } \\
\text { case }\end{array}$ & 38.8 & 6.5 & 23.2 & 7.9 \\
\hline proportion who had & 6.1 & 6.5 & 5.2 & \\
\hline
\end{tabular}

All figures represent percentage (\%) for each category of hospital staff

After injury only26 (20.7\%) gottheir blood tested immediately after the injury and only 35 (27.5\%) reported the cases.

\begin{tabular}{|lll|}
\hline $\begin{array}{l}\text { Table 3 } \\
\text { Responses taken after the needle } \\
\text { stick injury }\end{array}$ & $\mathrm{N}$ & $\%$ \\
Response after the injury & 16 & 14.8 \\
Nothing & 11 & 8.6 \\
Washed hand & 51 & 39.8 \\
With soap and water & 16 & 10.5 \\
Applied spirit & 1 & 0.3 \\
Pep & 17 & 13.7 \\
Water, soap and spirit & 6 & 4.3 \\
Water and spirit only & 8 & 6.3 \\
Water, soap, spirit and pep & \\
$\begin{array}{l}\text { Note: The total does not sum up to } \\
\text { infrequent were not shown }\end{array}$ & \\
\hline
\end{tabular}

\section{Discussion}

A large number of workers have being reported to have had needle stick injuries in their career.

In this study 36 workers among 161 health care workers have had needle stick injuries within the past 1 month, giving a rate of about $3.47 \%$ per annum. Only $27.5 \%$ said to have reported the case. Pournaras et al. had found the incidence of NSI to be $2.4 \%$ per year, but which they themselves discuss to be apparent underreporting as they considered only reported incidents ${ }^{8}$.Study by WHO on global burden of sharp injury estimated the average number of injuries per health care worker in Africa is 2-4 sharps injuries per year on average. ${ }^{7}$

Preventive practices like wearing of gloves is known to be important line of defense, but higher numbers of nurses and lab technicians have not been practicing it.

Training programs should be encouraged and it should be emphasized that need to maintain utmost care and caution in handling needle sticks or sharps are paramount.

About $50.4 \%$ of health care worker who ascribed their injuries to being fatigue, have being found to having long working hours. The hospital system has a hectic and stressful system and due to the long hours of duty, it must be ensured health workers should be given breaks in between work, to refresh themselves up.

Other studies shows recapping as an important cause of $\mathrm{NSI}^{12}$, so training and retraining of staff should be emphasized. 
Texila International Journal of Clinical Research

Volume 3, Issue 2, Dec 2016

Previous studies too have shown a wide difference in the occurrence rate of NSI in the studies which asked directly from the HCWs compared to those relying only on those who self -reported to the institution. ${ }^{11}$

Needle stick injuries are important occupational hazard that health care workers face daily, but can be minimized to a large extent. So prevention of injuries is the best way to prevent several diseases in the health care workers.

It is recommended that government should make policies that would enforce all hospital management to develop a multi-pronged strategy to deal with needle stick injuries, and also promoting health and setting up an adequate surveillance mechanism.

\section{Conclusion}

Occurrence of needle stick injuries was found to be common.

Recapping of needles which is an avoidable practice was found to be part of the contributing factors to the injuries.

Therefore prevention of needle stick injuries is an integral part of preventive

programs and training and retraining of health care works for safety practices in handling needles and sharp objects needs to be continuous in the hospital

\section{References}

[1]. Adeboye AA, Moss GB, Soyinka F, Kreiss Jk. The epidemiology of needlestick and sharp instrument accidents in Nigerian Hospital. Infect Control Hosp Epidemiol 1994; 15:27-31

[2]. British journal of medicine(occupational and environmental medicine);Journal List > Br.J Ind Med > v.44(8).1987 Aug

[3]. CCOHS; Canadian Center for occupational health and safety. https://www.ccohs.ca/oshanswers/diseases/needlestick. Copyright 1997-2016

[4]. Elder A, Paterson c. Sharp injuries in UK health care: A review of injury rates, viral transmission and potential efficacy of safety devices. Occup Med (Lond) 2006;56:566-74

[5]. Ganczak M., Bohatyrewicz A., Korzen M., Karakiewicz B. The comparison of sharp injuries reported by doctors versus nurses from surgical wards in the context of the prevalence of HBV, HCV and HIV infections.

Pol Przegl Chir. 2012;84:190-195.(PubMed)

[6]. Gestal JJ. Occupational hazards in hospital: risk of infection. Br J Ind Med 1987 jul

[7]. Henderson D.K. management of needlestick injuries. JAMA.2012;307:75-84(PubMed)

[8]. Kirchner, B(2012). Safety in ambulatory surgery centers: Occupational safety and Health Administration surveys”. AORN Journal. 96: 540-5.

[9]. OSHA USD of Labour? www.osha,gov/SCTc/etools/hazards

[10]. Occupational health, safety and hygiene- The Carter center. www.cartercenter.org>org>lecture_notes

[11]. Pruss- ustun A, Rapiti E, Hustin Y. sharps injuries; global burden of disease from sharps injuries to health - care workers. Geneva: WHO; 2003(Who Environmental Burden of Disease Series, No.3)

[12]. Pournaras S, Tsakris A, Mandreveli K, Faitatzidou A, Douboyas J, Tourkantonis A. Reported needlestick and sharp injuries among health care workers in Greek general hospital. Occup Med (Lond) 1999;49;423-6 